\title{
El consumo de azogue: ¿Indicador de la corrupción del sistema colonial en el virreinato del Perú? (Siglos XVI-XVII)
}

\author{
Héctor Omar Noejovich \\ Pontificia Universidad Católica de Lima \\ hnoejov@macareo.pucp.edu.pe
}

Fecha de recepción: 15 de mayo de 2002

Fecha de aceptación: 1 de octubre de 2002

\begin{abstract}
Resumen
A partir del estudio de la minería de la plata en Potosí durante el siglo XVII, este trabajo trata sobre el concepto de corrupción, e intenta establecer su magnitud a través de la relación entre el azoque y la plata involucrada en el proceso de amalgamación. Partiendo de una serie de datos cuantitativos se establece la existencia de diferencias en la relación mercurio/plata desde el punto de vista químico, empírico e institucional. Utilizando instrumentos estadísticos se establece un "margen de fraude" que, a lo largo del siglo XVII, dependió de las negociaciones entre los mineros y los funcionarios públicos; y contribuyó al comercio ilegal a través de Buenos Aires. Las conclusiones estiman la tendencia de la plata registrada (o plata legal) en la Caja Real de Potosí y la comparan con la tendencia proyectada de la producción total con base en el consumo del azogue (producción de Huancavelica mas las importaciones menos las exportaciones).
\end{abstract}

Palabras clave: AZOGUE, MERCURIO, MINERÍA DE LA PLATA, CORRUPCIÓN, POTOSÍ, PERÚ, SIGLO XVI, SIGLO XVII.

\begin{abstract}
This paper deals with the concept of corruption, trying to assess its magnitude by analyzing the relationship between mercury and silver used in the process of extraction. Using quantitative data, chemical, empirical and institutional differences are established for the mercury to silver ratio. Through statistical analyses, a "margin of fraud" is also established. Throughout the $17^{\text {th }}$ century, this margin depended on negotiations between miners and public officials and contributed to the illegal trade through Buenos Aires. The conclusions estimate the tendencies of registered silver (or legal silver) in the Potosí royal treasury, comparing it against the projected tendency of total production based on mercury consumption (that produced in Huancavélica added to imports minus exports).
\end{abstract}

Key words: AZOGUE, MERCURY, SILVER MINNING, CORRUPTION, POTOSÍ, PERU, $16^{\mathrm{TH}}$ CENTURY, $17^{\mathrm{TH}}$ CENTURY.

Fronteras de la Historia 7 (2002)

(C) ICANH 


\section{Presentación del problema}

Corrupción es un vocablo de acepciones variadas. Indica putrefacción, descomposición. En términos sociales modernos identificamos la palabra con el cohecho, el soborno del funcionario, la ilegalidad. Pero ello no es simplemente así: la corrupción va más allá de la simple dádiva para obtener un fin que las normas institucionales consideran ilícito. Este último es un hecho punible por las normas; pero, ¿hay normas corruptas? Por cierto que las hay: son aquellas que corrompen el sistema, son aquellas que destruyen los valores sobre los cuales está construida una sociedad.

La simple dádiva no es necesariamente un soborno y mucho menos una manifestación de corrupción dependiendo, obviamente, del contexto. Por ejemplo, si el sistema se sustenta en intercambios del tipo "toma y daca", como los denomina Belshaw", un observador occidental puede interpretarlo como un soborno. Es la racionalidad de ese sistema ${ }^{2}$ la que determina las reglas de los intercambios que ocurren en la matriz social; su inobservancia será, en esos casos, el ilícito punible.

Otro caso es el "invite de coca", como inicio de una relación de reciprocidad y, modernamente, de intercambios"; ese "invite" los españoles lo interpretaron como "pago" y de allí que algunos cronistas mencionaban a la "coca" como "moneda". También un observador actual que desconozca las reglas puede interpretarlo así, catalogándola como una "seducción" para promover a la otra parte. Dado que se hace "por adelantado", en determinadas circunstancias podría catalogarse, en términos occidentales, como un "soborno". Esa interpretación sería errónea, pues se trata simplemente de cumplir con las normas sociales.

¿Pero qué sucede cuando esas reglas, a su vez, subvierten el orden del sistema? Veamos un ejemplo en América colonial. Levene ${ }^{5}$, para comienzos del siglo XVII, refiere un informe del Obispo al Cabildo de Buenos Aires:

El fin que tiene el Rey nuestro Señor como católico y cristianísimo en las cédulas que despacha es el servicio de Dios Nuestro Señor y el bien y aumento de la

\footnotetext{
- Versiones preliminares de este trabajo se presentaron en el V Congreso Internacional de Etnohistoria, San Salvador de Jujuy, Argentina, 1998 y en la VI Reunión de Historiadores de la Minería Latinoamericana, Lima, Perú, 1999.

${ }^{1}$ Cyril Belshaw, Comercio tradicional y mercados modernos (Barcelona: Labor, 1972), 63.

${ }^{2}$ Cf. Maurice Godelier, Racionalidad e irracionalidad en economía (México: Siglo XXI, 1976).

${ }^{3}$ Cf. Roderick E. Bruchard, "Coca y trueque de alimentos" en Giorgio Alberti y Enrique Mayer, eds., Reciprocidad e intercambio en los Andes (Lima: Instituto de Estudios Peruanos, 1974).

${ }^{4}$ Juan Torquemada, Monarquía Indiana, 3 vols. (México: Porrúa, 1986 [1615]), 2:579; Matienzo, Gobierno del Perú (París-Lima: Instituto Francés de Estudios Andinos, 1967 [1567]), 164. Para un análisis de la "moneda precolombina", ver Héctor Omar Noejovich, Los albores de la economía americana (Lima: Fondo Editorial PUCP, 1996), 194 y ss.

${ }^{5}$ Ricardo Levene, Introducción a la historia del Derecho Indiano (Buenos Aires: Valerio Abeledo, 1976), 31.
} 
república y de sus vasallos... si alguna cédula emanase contraria a este fin sería por falsa y siniestra información y los gobernadores la an de reverenciar pero no executalla, en cuanto es repugnante a dicho fin... que no se han de executar algunas cédulas reales con todo el rigor que la letra pareze significar, si no antes se ande ynterpretar ${ }^{6}$.

Opiniones concordantes se encuentran en tratadistas como Solórzano y Bovadilla, así como también en la Recopilación de Leyes de Indias. La norma, en este caso la Cédula Real, debe ser respetada "excepto si" es "contraria al bien", para lo cual se debe "interpretar". El justificativo es la "falsa información" que pudo haber tenido el Rey al emitirla.

La hermenéutica queda en manos de las autoridades que aplican la norma; son ellos quienes tienen, de esa manera, la facultad de decisión acerca de "ejecutarla" y de graduar el "rigor". Siendo así, el "ilícito" se produce cuando los agentes actúan contrariamente a la interpretación del funcionario y no frente al contenido de la norma. De allí, al "influenciar al funcionario" para que dirija la "interpretación" hacia determinados intereses, hay sólo un paso y una línea muy sutil, difícil de precisar, entre la "racionalidad del agente" y la "racionalidad del sistema"

Esto se expresaba en el principio general de que la "ley se obedece pero no se cumple" ${ }^{8}$, el cual, desde un punto de vista moderno, muestra una normatividad "relajada" catalogable como una forma de corrupción, entendida ésta como la degradación de la norma. Esta actitud, a su vez, corrompe al sistema.

Si es lícito no observar una norma porque es perjudicial a los intereses personales y su justificación es que fue emitida por desconocimiento de la realidad de "esta república y sus vasallos". ¿Dónde estaba el límite entre lo permitido y lo prohibido? ¿En qué consistía el ilícito punible? ¿Cuándo podemos hablar de corrupción? ${ }^{9}$

\footnotetext{
6 “Acuerdos del extinguido Cabildo de Buenos Aires”, Edición del Archivo General de la Nación, I, 193, citado en Ibídem.

${ }^{7}$ Cf. Godelier, Racionalidad.

${ }^{8}$ El acatamiento de las Cédulas Reales tiene una connotación medieval. Se reverenciaba al soberano, como parte del homenaje que implicaba el vasallaje, no solamente en su persona física, sino en sus disposiciones. Pero ese ritual quedó reducido a una formalidad, apartándose de la aplicación práctica.

${ }^{9}$ Otro tipo de enfoque lo encontramos en Horst Pietshmann, "Burocracia y corrupción en Hispanoamérica colonial. Una aproximación tentativa", Nova americana, no. 5 (1982): 11-37; Horst Pietshmann, Burocracia y corrupción (México: Fondo de Cultura Económica, 1987). Zacarías Moutoukias, "Power, Corruption, and Commerce: The Making of the Local Administrative Structure in Seventeenth Century Buenos Aires", Hispanic American Historical Review 668, no. 4 (1988): 771-801. Para éste último la "corrupción" consolida el "pacto colonial", en tanto que para el primero la "venalidad y la corrupción" fueron elementos dinamizantes. Una discusión sobre esta visión puede verse en Estela Cristina Salles y Héctor Omar Noejovich, "Santiago y Buenos Aires: la actividad económica en la frontera sur del virreinato del Perú", Economía XXII, no. 43 (1999): 211-215. Asimismo, existen teorías que ligan la corrupción de los estados republicanos a su pasado español como las señaladas en Walter L. Bernbecker, "Contrabando, legalidad y corrupción en el México decimonónico" Historia y Grafia 1, no. 1 (1998). Finalmente, otros autores prefieren describir casos específicos, como Leticia Vacary de Venturini, Sobre gobernadores y rendición en la Provincia de Venezuela. Siglos XVI, XVII y XVIII (Caracas: Academia Nacional de Historia, 1993); y
} 
Respecto del contrabando, del fraude de moneda y de las demás transgresiones en el ámbito colonial, ¿cómo diferenciar entre la "corrupción" y la "inobservancia de la norma por ser perjudicial"? Si nos ubicamos en el mundo actual ${ }^{10}$, todo el sistema sería corrupto, toda vez que las normas se cumplían en forma relativa; es decir, si no atentaban contra intereses personales.

Veamos otro interesante caso. Francisco Fernández de la Rocha, alcalde de Potosí, encabezó el fraude monetario generalizado a mediados del siglo XVII. La adulteración de la moneda, disminuyendo el contenido de plata fina fijado por las disposiciones legales, había sido ya percibida por las administraciones de Luis de Velasco (1596-1604) y del Marqués de Montesclaros (1607-1615) ¿ ¿Una ciudad entera participando de la adulteración durante 50 años y el Alcalde encabezando el fraude? Esa parece ser la evidencia. No se trataba solamente de "falta de autoridad", como se quejaban los virreyes, sino de un consenso generalizado.

Obviamente ese "fraude" iba en beneficio de la población, especialmente de los azogueros ${ }^{12}$. Juzgado este incidente a la luz de esos principios de relatividad en el cumplimiento de las normas, el juzgamiento y ajusticiamiento de Fernández de la Rocha parece haber sido por el "exceso de fraude" y no por el ilícito en sí mismo ${ }^{13}$.

En esta tesitura es difícil catalogar el ilícito en forma tajante, como sugieren las normas precisas de un derecho positivo. Existe una suerte de "margen", más o menos tolerado por las autoridades. El provecho personal de esa "tolerancia", por parte de los funcionarios es, a mi entender, un elemento secundario. En efecto, la corrupción se presentaría, así, como una "corrupción del sistema", con unos "márgenes de tolerancia" que hacen impreciso el cumplimiento de las normas y conforman una estructura institucional débil y represiva. Esta conjunción entre "debilidad institucional" y "represión", de apariencia contradictoria, se presenta como el rasgo distintivo de la sociedad colonial, cuyo legado es de notoria influencia en tiempos actuales.

\footnotetext{
Luis Jorge Ramos Gómez, "La acusación contra el Presidente Electo Dn. José Araujo y Río, sobre la introducción de mercancías ilícitas a su llegada a Quito en diciembre de 1736", Boletín de la Academia Nacional de Historia, no. 72 (1993). Frente a esta literatura, como así también a la contemporánea, estamos desarrollando nuestra propia categorización de la corrupción.

${ }^{10}$ Existen múltiples trabajos sobre el tema, especialmente para los siglos XIX y XX; soslayamos esa bibliografía por considerar que, en sí, la corrupción no está en discusión, sino nuestra propia interpretación.

${ }^{11}$ Manuel Moreyra y Paz Soldan, La moneda colonial en el Perú (Lima: Banco Central de Reserva, 1980)118 y ss.

${ }^{12} \mathrm{Al}$ fin y al cabo, siendo la plata un producto de exportación, su comportamiento era el de cualquier exportador contemporáneo: propugnaban por una devaluación.

${ }^{13}$ En las haciendas del siglo XIX y XX existen innumerables referencias sobre condenas a peones yanaconas "porque robaban demasiado". Los robos sistemáticos en fábricas, en el Perú actual, son materia de preocupación cuando "se pasan". La adulteración de las pesas en los mercados es común: hay sitios de "buena pesada" y sitios que tienen "mala pesada". Sucede también a niveles mayores, como en el caso de la pesca. Héctor Omar Noejovich, "Normatividad, institucionalidad y tecnología: el comportamiento peculiar de agentes en la industria pesquera", Economía XIV, no.28 (1997):351.
} 
Curiosamente, la sociedad indígena también se asentaba en límites imprecisos, dejando un "margen para un área de negociación"14, la cual era necesaria para su funcionamiento. En efecto, el dualismo andino requiere de una flexibilización en las estructuras de comportamiento, con el fin de poder nivelar los intereses del grupo ${ }^{15}$. Este comportamiento anfibológico ${ }^{16}$ no constituye, empero, una forma de corrupción, sino que es inherente a la dinámica de esa sociedad. En este punto se articularon la "república de españoles" y la "república de indios", toda vez que, aunque con motivaciones distintas, existieron "áreas de coincidencia". Un ejemplo de ello, y además un punto de partida para una hipótesis interpretativa, está en el caso de los indios de faltriquera. Estos fueron el resultado de una "negociación" entre los azogueros y los jefes étnicos. Dicho comportamiento está catalogado como una forma de corrupción ${ }^{17}$ pero, al mismo tiempo, puede ser visto como una "defensa" de la población indígena. La estrategia de conmutar la mita por plata, primero, y eliminar el pago, después, revela cierta capacidad de "negociación" aprovechando el "margen" establecido por la normatividad ${ }^{18}$.

En definitiva, conceptuar de "corrupta" a la sociedad colonial del siglo XVI-XVII, es juzgarla desde una perspectiva epistemológica contemporánea. Como es imposible despercudirse de esta última, sólo nos resta tener presente las consideraciones expuestas y, en lo posible, matizar los juicios que emitamos.

\section{El concepto de "margen de fraude"}

Para soslayar la discusión esbozada en las líneas que anteceden, propongo trabajar sobre la base de un "coeficiente" estimado de lo marginal, que denomino margen de fraude. Es decir, aquello que estaba "fuera de la ley", pero que era público y notorio, además de tolerado por el sistema, siempre que no se "excediera" de los límites socialmente establecidos ${ }^{19}$.

Sobre la misma base discutí anteriormente el problema de las "mentiras de los indios"20. El caso se refería al análisis de los testimonios contenidos en la Visita a la Provincia de León de

\footnotetext{
${ }^{14}$ Que he denominado buffer-zone. Héctor Omar Noejovich, "El pensamiento dual andino y sus implicaciones socioeconómicas", Histórica XIX, no. 1 (1995): 106.

${ }^{15}$ Noejovich, Los albores, 404 y ss.

${ }^{16}$ Ibídem.

${ }^{17}$ Cf. Luis Miguel Glave, "El virreinato peruano y la llamada 'crisis general' del siglo XVII", en Heraclio Bonilla, Las crisis económicas en la historia del Perú (Lima: Fundación Friedrich Ebert, 1986), 109 y ss.

${ }^{18}$ En 1659, Francisco de la Cruz fue comisionado por el virrey Conde de Alba de Liste para terminar con esa práctica; fue asesinado el 23.04.1660. Esa misma noche murió el Presidente de la Audiencia, Nestares Marín, quién había tenido a su cargo el procesamiento y ejecución de Gómez de la Rocha, en 1654 (Cf. Jeffrey A. Cole, The Potosí Mita, 1573-1700 (Stanford: Stanford University Press, 1985), 93.

${ }_{19}$ A nivel coloquial es común escuchar, en el Perú contemporáneo, frente a casos de corrupción de funcionarios públicos: "se pasó, robó demasiado". Sugiere la idea de una "tolerancia social" al peculado.

${ }^{20}$ Noejovich, Los albores, 404 y ss.
} 
Huánuco de $1562^{21}$. En el citado documento ${ }^{22}$, confrontamos lo dicho por los jefes étnicos con los pareceres del visitador y los testimonios de las 864 casas visitadas. Estos dos últimos tenían poca discrepancia entre $\mathrm{si}^{23}$. La diferencia se hizo notoria al comparar los testimonios de los jefes étnicos con los testimonios individuales, casa por casa, específicamente en dos aspectos: la población y el tiempo empleado para darle el tributo al encomendero.

Para la población, la "mentira" era uniforme: los jefes étnicos disminuían el número de mujeres en sus manifestaciones. En el segundo caso, también era uniforme el sesgo de las declaraciones provenientes de los jefes étnicos, quienes exageraban el "agravio que le produce a los indios" el tributo. La prueba estadística entre ambos testimonios fue clara: mientras los testimonios individuales sobre el tiempo empleado en el tributo mostraron promedios uniformes, los testimonios de los jefes étnicos indicaron un sesgo estadísticamente verificable ${ }^{24}$. Además, esto se corroboró en las opiniones sobre el "agravio que le produce el tributo" 25 .

Esto quiere decir que los jefes étnicos "mentían uniformemente", como parte de una estrategia. Ese comportamiento fue susceptible de apreciación estadística, estableciendo un rango dentro del cual fluctúa la mentira. En la misma línea, el objeto de este trabajo es intentar establecer un rango dentro del cual fluctúa el fraude perpetrado por los mineros potosinos en agravio de la Corona. En otros términos: ¿Qué representó la evasión del quinto real? ¿Era una práctica esporádica o errática? ¿Estaba "institucionalizada" dentro del sistema? En el caso de considerar afirmativo este último interrogante, ¿era realmente una corruptela? ¿O debe interpretarse como la expresión de una economía "informal", parte de una estrategia de los agentes económicos, con un "margen de tolerancia"?

El consumo de azogue, en tanto insumo utilizado en la producción de plata, nos proporciona un referente importante, ya que fundamentalmente depende de una relación química. Nuestro análisis estriba en estimar los márgenes dentro de los cuales osciló esa relación. Los márgenes estadísticamente estimados proporcionan una aproximación a nuestro concepto de margen de fraude.

\footnotetext{
${ }^{21}$ John V. Murra ed., Visita a la provincia de León de Huánuco en 1562. Iñigo Ortiz de Zuñiga, visitador, 2 t. (Huánuco: Universidad Nacional Hermilio Valdizán, 1967).

${ }^{22}$ Debemos recordar que el intérprete era don Gaspar de Rodas, "griego al servicio de su Magestad". Allí puede haber un sesgo, derivado de su traducción del quechua al español, pero este también debe suponerse constante.

${ }^{23}$ No superior al $5 \%$.

${ }^{24} \mathrm{El}$ análisis de frecuencia se realizó considerando 93 testimonios individuales y 47 testimonios de los jefes étnicos. En la distribución de frecuencias correspondientes a los primeros la asimetría fue inexistente, en tanto que en la correspondiente a los segundos fue positiva $(+1,9)$. Noejovich, Los albores, 493.

${ }^{25}$ Sobre 379 opiniones individuales, 227 se pronunciaron por el "agravio" (60\%); de los 53 testimonios vertidos por los jefes étnicos, 45 manifestaron que el "tributo causaba agravio a los indios" (85\%) Noejovich, Los albores, 494.
} 


\section{La estimación}

\section{La relación técnica azogue/plata}

Se acepta generalmente ${ }^{26}$ que ésta era de 1 Libra de azogue por 1 Marco de plata $^{27}$. Lang diferencia entre el mercurio consumido, correspondiente a la reacción química propiamente dicha, y el perdido, consecuencia del procedimiento mismo, según los distintos métodos de amalgamación y el tipo de mineral ${ }^{28}$.

Según Lang, el consumido era en proporción 1:1, en tanto que añadiendo el perdido, el total empleado era de 12 a 14 onzas de mercurio por marco. Esto significaría un intervalo comprendido entre las proporciones $1,5: 1$ y $1,75: 1^{29}$. En un documento publicado por Lohmann $^{30}$, sobre la base de la producción entre 1571 y 1696, el funcionario utilizó una relación $1: 1$, con una merma del $25 \%$, que arrojaría una proporción de 1,33:1.

Pero existe otro elemento más. Si bien el proceso de patio, mediante la amalgama azogue/plata se implementa para el virreinato del Perú en 1571, el antiguo procedimiento de la huayra no desapareció totalmente, en especial para el mineral de alta ley, en el cual seguía siendo rentable. El impacto en la producción de plata, por el cambio tecnológico, se aprecia en el gráfico siguiente $^{31}$.

\footnotetext{
${ }^{26}$ Guillermo Lohmann Villena, Las minas de Huancavelica (Sevilla: Escuela de Estudios Hispano-Americanos, 1949), 56. John Fisher, Minas y mineros en el Perú colonial (Lima: Instituto de Estudios Peruanos, 1977), 152 y ss. Para una comparación entre México y Perú, ver Héctor Omar Noejovich, "Producción de plata y consumo de azogue: una comparación entre el virreinato del Perú y el virreinato de la Nueva España bajo los Austrias", Investigación Económica XLI, no.235 (2001): 161-199.

${ }^{27}$ Hemos hecho una reducción hacia una medida común. Cuando se trata de plata el peso se da en marcos y cuando se trata de azoque se mide en libras. Ambas se inscriben en una unidad mayor que son los quintales (100Libras)Dado que 1 Libra=2 Marcos=16 Onzas (Noejovich, Los albores, 183 y ss), en adelante diremos que la relación es 2:1. Cuando se menciona en los textos y documentos "1 Libra de azogue por un Marco de plata", dado que ambas medidas son usadas en sentido ponderal, estamos diciendo: "2 Marcos de azogue por un Marco de plata". De allí el 2:1.

${ }^{28}$ Para una descripción, entre otros, ver Gwendolyn Ballantine Cobb, Potosí y Huancavelica (La Paz: Banco Minero de Bolivia, 1977), 81 y ss. Mervyn F. Lang, El monopolio estatal del mercurio en el México colonial (México: FCE, 1977), 50

${ }^{29}(12$ Onzas $/ 1$ Marco=8Onzas $)=1,5 ;(14$ Onzas $/ 1$ Marco $=8$ Onzas $)=1,75$

${ }^{30}$ Lohmann, Las minas, 448: Razón de lo que produjo al Tesoro público la mina de Huancavelica, tanto en mercurio, como la plata que con el se benefició (AGI, Lima, 469).

${ }^{31}$ Todas las series y gráficos sobre la producción de plata han sido deducidas del "Manifiesto de los productos que ha rendido el Cerro de Potosí desde su descubrimiento año de 1555 hasta el de 1789, y el origen de dicho descubrimiento, por certificación del Tesorero Dn Lamberto de Sierra", en Moreyra, La moneda, 263 y ss.
} 


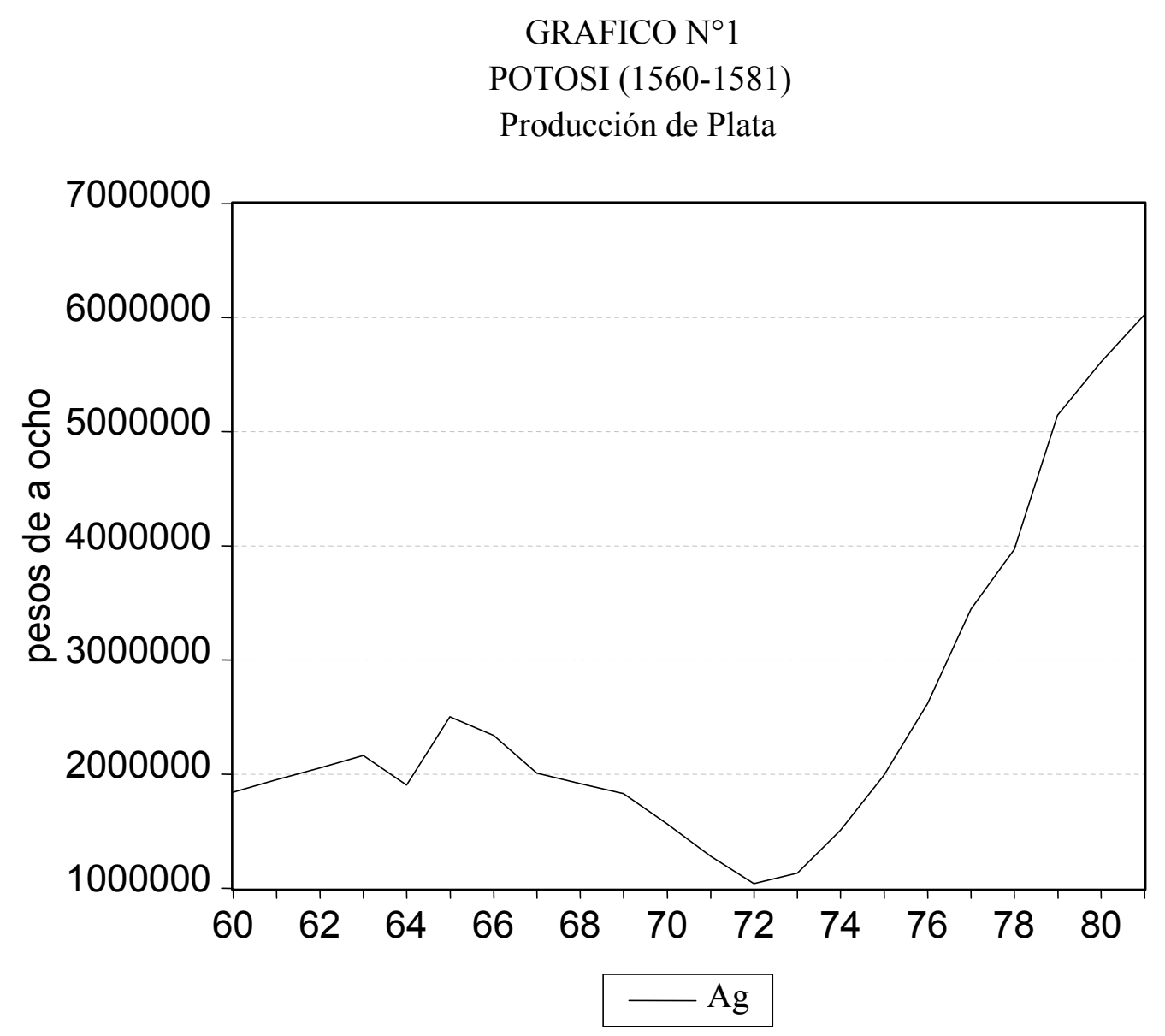

Fuente: "Manifiesto de los productos que ha rendido el Cerro de Potosí desde su descubrimiento año de 1555 hasta el de 1789, y el origen de dicho descubrimiento, por certificación del Tesorero Dn Lamberto de Sierra“, en Manuel Moreyra y Paz Soldan, La moneda colonial en el Perú (Lima: Banco Central de Reserva, 1980), 263 y ss.

El nivel mínimo a que llegó la producción, en 1572, fue aproximadamente 1/6 del alcanzado al final del virreinato de Toledo. Obviamente estaba descendiendo, hasta el punto que, según Cobb, el precio del quintal de mineral descendió de 100 a 2 marcos ${ }^{32}$. Además, de acuerdo con una carta de Diego Cabeza de Baca al virrey, en 1581, la fundición por medio de las huayras había sido abandonada ${ }^{33}$. Acosta refiere una reducción de las huayras de "más de seis mil" a "mil o dos mil, como mucho" ${ }^{34}$. Esa reducción no afecta la relación de causalidad entre el

\footnotetext{
${ }^{32}$ Cobb, Potosí, 88. El precio está dado en "marcos de plata".

${ }^{33}$ Ibídem, 87.

${ }^{34}$ Joseph de Acosta, Historia moral y natural de las Indias, Edición de Edmundo O’Gorman (México: FCE, 1962 [1590]).
} 
aumento de la producción indicado, como consecuencia de la introducción del proceso de amalgama. La continuación de las huayras y su progresiva reducción, explicarían por qué en la $1^{\text {a }}$ Etapa (1571-1604), el perdido era mucho menor que en las siguientes ${ }^{35}$.

De cualquier manera, para efecto de establecer la relación azogue/plata, desde las estadísticas globales disponibles, a partir de 1572, podemos obviar la producción por los métodos tradicionales, ya que no parecen haber sido muy significativos, especialmente durante el transcurso del siglo XVII ${ }^{36}$.

\section{Los puntos de partida}

La utilización de las minas de Huancavelica, asumidas como monopolio estatal, fue uno de los pilares de la política de Toledo ${ }^{37}$. Sin embargo, la evidencia muestra que su producción parecía haber sido insuficiente, recurriéndose a la importación. Veamos gráficamente esta situación ${ }^{38}$.

\footnotetext{
${ }^{35}$ Cf infra, Cuadro $\mathrm{N}^{\circ} 1$.

${ }^{36}$ En todo caso, incidirían a favor de una reducción en la relación azogue/plata, ya que tendríamos plata producida sin azogue.

${ }^{37}$ Héctor Omar Noejovich, “La política minera del virrey Toledo: un ensayo económico”, Economía XIX, no. 37-38, (Junio de 1998).

${ }^{38}$ La fuente para la estimación de azogue es el documento titulado "Razón del azogue que se ha sacado de la Real Mina de Guancabelica y enterado y quintado en las Reales Cajas della“ (BNM, Ms. 2784, f f 517/20). Citado en Lohmann, Las minas, 452.
} 


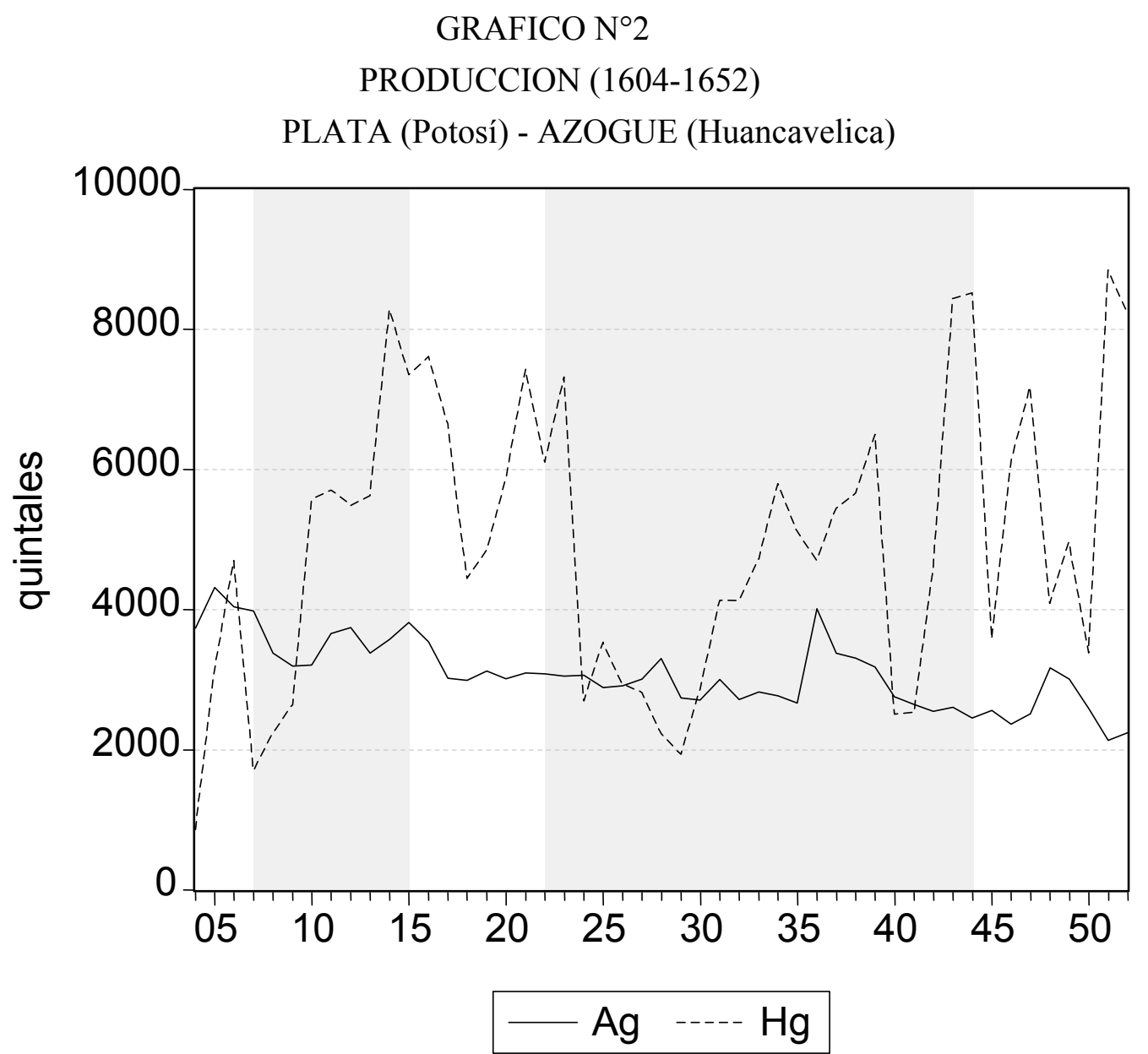

Fuente: "Manifiesto", Moreyra, La moneda, 263 y ss.

Las áreas sombreadas corresponden a los períodos en que se registran importaciones ${ }^{39}$. Lang, por su parte, señala que esas importaciones fueron necesarias hasta 1650, especialmente entre 1630 y 1633, cuando el mercurio estaba tan escaso en el Perú, que además del que se importaba de Europa el virrey trató de obtener que de México le llegara un abastecimiento con urgencia ${ }^{40}$.

\footnotetext{
${ }^{39}$ Carlos Contreras Carranza, El azogue en el Perú colonial, 1570-1650 (Tesis inédita, Lima: Pontificia Universidad Católica, 1981), 146.

${ }^{40}$ Lang, El monopolio, 100.
} 


\section{GRAFICO N³}

\section{IMPORTACION DE AZOGUE Y PRODUCCION DE PLATA}

$(1607-1652)$

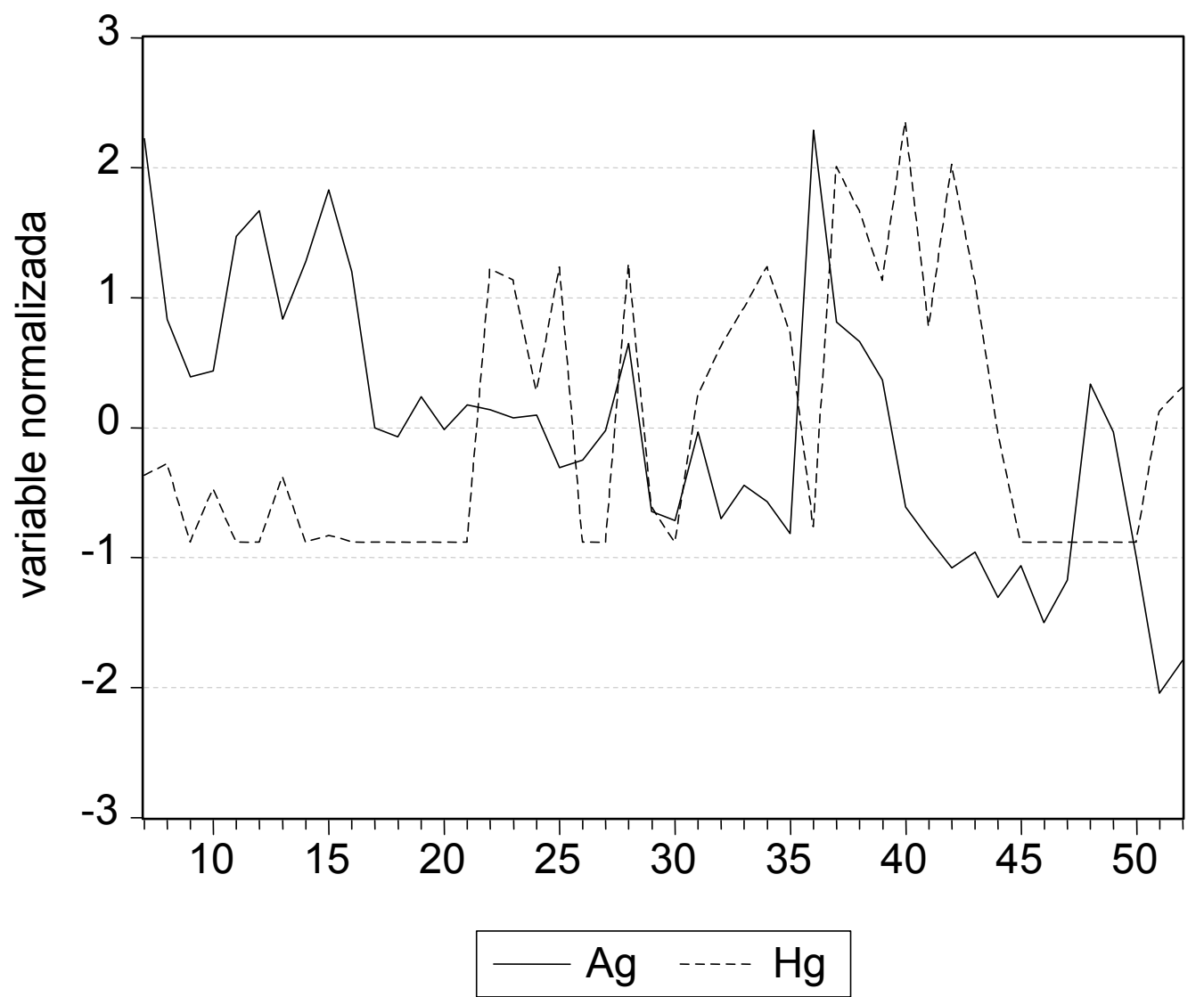

Fuente: Carlos Contreras Carranza, El azogue en el Perú colonial (1570-1650) (Tesis inédita, Lima: Pontificia Universidac Católica, 1981), 146 y “"Manifiesto“", en Moreyra, La moneda, 263 y ss.

Como se puede apreciar visualmente, estas afirmaciones son contradictorias con la evidencia. Salvo cortos períodos, 1606-10 y 1624-30, la producción de azogue superó la producción de plata; es decir, que era mayor que el consumido originado en razones técnicas. La diferencia sólo puede estar en el perdido. Llama poderosamente la atención que las importaciones crecieron, precisamente, cuando disminuyó la producción de plata registrada. 
El gráfico $\mathrm{N}^{\circ} 3$ está presentado en forma normalizada ${ }^{41}$ para poder visualizar la disminución de la producción de plata frente al aumento de la importación de azogue. El fenómeno parece claro: hay una clara presunción de fraude en la modalidad de plata producida y no registrada, amén del posible fraude de azogue no registrado.

Después de 1670, el virreinato del Perú reanudó las exportaciones de azogue al virreinato de la Nueva España, las mismas que se habían interrumpido en 1603. Esta primera década del siglo XVI indica el cierre de una etapa, que coincide con el término de la gestión virreinal de Luis de Velasco (1604), de la cual tenemos una estimación de la existencia de azogue, entre 27 y 30 mil quintales, al finalizar la misma ${ }^{42}$.

Tenemos una segunda etapa, entre 1604 y 1639. En este último año, el Conde de Chinchón finalizó su gestión y las existencias de azogue almacenadas eran de 24.000 quintales. El otro inventario que disponemos es el del virrey Mancera, en 1648, que indica entre 25 y 36 mil quintales de mercurio ${ }^{43}$.

Definimos una tercera etapa, 1639-48, que coincide con los años álgidos de adulteración monetaria. Una etapa final, de 1648 a 1700, que corresponde, nuevamente, con un período de exportación de azogue. Resumimos:

\section{CUADRO $N^{\circ} 1$ \\ EL AZOGUE (1571-1700) Y SU RELACION CON LA PLATA REGISTRADA (en miles de quintales)}

\begin{tabular}{|l|l|l|l|l|}
\hline CONCEPTO & $\begin{array}{l}\mathbf{1}^{\text {a }} \text { ETAPA } \\
\mathbf{( 1 5 7 1 - 1 6 0 4 )}\end{array}$ & $\begin{array}{l}\mathbf{2}^{\mathbf{a}} \text { ETAPA } \\
(\mathbf{1 6 0 5 - 1 6 3 9})\end{array}$ & $\begin{array}{l}\mathbf{3}^{\mathbf{a}} \text { ETAPA } \\
\mathbf{( 1 6 4 0 - 1 6 4 8 )}\end{array}$ & $\begin{array}{l}\mathbf{4}^{\mathbf{a}} \text { ETAPA } \\
(\mathbf{1 6 4 9 - 1 7 0 0 )}\end{array}$ \\
\hline pRODUCCIÓN & 187,1 & 168,0 & 47,5 & 272,2 \\
\hline$(-)$ EXPORTACION & 18,5 & ------ & ---- & 27,0 \\
\hline (+) iMPORTACIÓN & ---- & 55,0 & 21,2 & 4,7 \\
\hline$(+)$ EXISTENCIA INICIAL & ----- & $27,0 / 30,0$ & 24,0 & $25,0 / 36,0$ \\
\hline$(-)$ EXISTENCIA FINAL & $27,0 / 30,0$ & 24,0 & $25,0 / 36,0$ & $25,0^{44}$ \\
\hline$(=)$ CONSUMO & $141,6 / 138,6$ & $226 / 229$ & $67,8 / 56,8$ & $249,9 / 260,9$ \\
\hline PLATA REGISTRADA & 117,0 & 119,0 & 24,7 & 100,5 \\
\hline RELACION HG/AG & $1,2: 1$ & $1,9: 1$ & $2,75: 1 / 2,3: 1$ & $2,5: 1 / 2,6: 1$ \\
\hline Perdido & $20 \%$ & $90 \%$ & $175 \% / 130 \%$ & $150 \% / 160 \%$ \\
\hline
\end{tabular}

Fuente: Hector Omar Noejovich, "Producción de plata y consumo de azogue: una comparación entre el virreinato del Perú y el virreinato de la Nueva España bajo los Austrias, Investigación Económica XLI, no. 235 (2001), 179.

\footnotetext{
${ }^{41}$ Centrado respecto de la media y ponderado por la dispersión $\sigma$.

${ }^{42}$ Contreras, El azogue, 146.

${ }^{43}$ Ibídem.

${ }^{44}$ Carezco del dato y asumo que el "stock" era constante. Este supuesto se apoya en los inventarios anteriores, cuyo orden de magnitud es semejante e induce a pensar en una política de existencias más o menos uniforme.
} 
Es claro que esa relación de 2:1, enunciada por la historiografía, no es más que una relación empírica que se verifica en el total y que deviene de una relación institucional ${ }^{45}$. En efecto, adicionando las cifras del cuadro anterior, el consumo de azogue resultaría de 709,6 miles de quintales, en tanto que la plata registrada ascendería a 361,2 miles de quintales. La descomposición por etapas nos revela una realidad muy distinta: las diferencias que surgen en el cuadro $\mathrm{N}^{\circ} 1$, respecto de la relación azogue/plata, muestran que tampoco se cumplía con la relación institucional.

Uno de los argumentos para explicar el ascenso del perdido es la producción por medio del método de la huayra, principalmente en la $1^{\mathrm{a}}$ etapa, cuando la ley minera era más rica. Esto nos conduce a otra explicación fundada en la disminución de la ley del mineral; si bien eso no altera el consumido, que responde a una relación química, influye en el perdido, toda vez que los procesos de fundición generan más escoria a medida que disminuye la ley del mineral. No obstante, dudo que se pueda llegar a esas magnitudes, especialmente cuando este aumento coincide con los fraudes en la moneda y en la mita. Por otra parte, se supone que con el tiempo la tecnología se perfecciona y es lógico suponer que se trate de ahorrar insumos y, por ende, el perdido no podía técnicamente alcanzar esos niveles.

En la descripción de un proceso de amalgamación, Garcí Sánchez, en Octubre de 1588, sobre un quintal de mineral, aconseja que se "use bastante mercurio: 8 libras de azogue cuando 6 son suficientes"46. Según Tandeter, para finales del siglo XVI y comienzos del XVII, los rendimientos "...habían sido del orden de los 50 marcos de plata pura por 'cajón' de 50 quintales de mineral..." ${ }^{47}$. Esto significa 5 libras de plata por quintal de mineral.

Comparado con la técnica aconsejada, si bien la relación resulta 1,2:1, la utilización de mayor cantidad de mercurio representa una relación de 1,6:1. Como se ve, está dentro de los parámetros indicados por Lang sobre la base de otras fuentes.

\footnotetext{
${ }^{45}$ Negociación entre funcionarios y azogueros para obtener una cuota del insumo en relación con la plata producida y registrada. La misma giraba en la proporción 2:1

${ }^{46}$ Cobb, Potosi, 162.

${ }^{47}$ Enrique Tandeter, Coacción y Mercado. La minería de plata en el Potosí colonial, 1629-1826 (Cusco: Centro de Estudios Regionales Andinos "Bartolomé de las Casas", 1992), 23.
} 


\section{GRAFICO No4 \\ PLATA REGISTRADA Y AZOGUE DISPONIBLE \\ (1571-1700)}

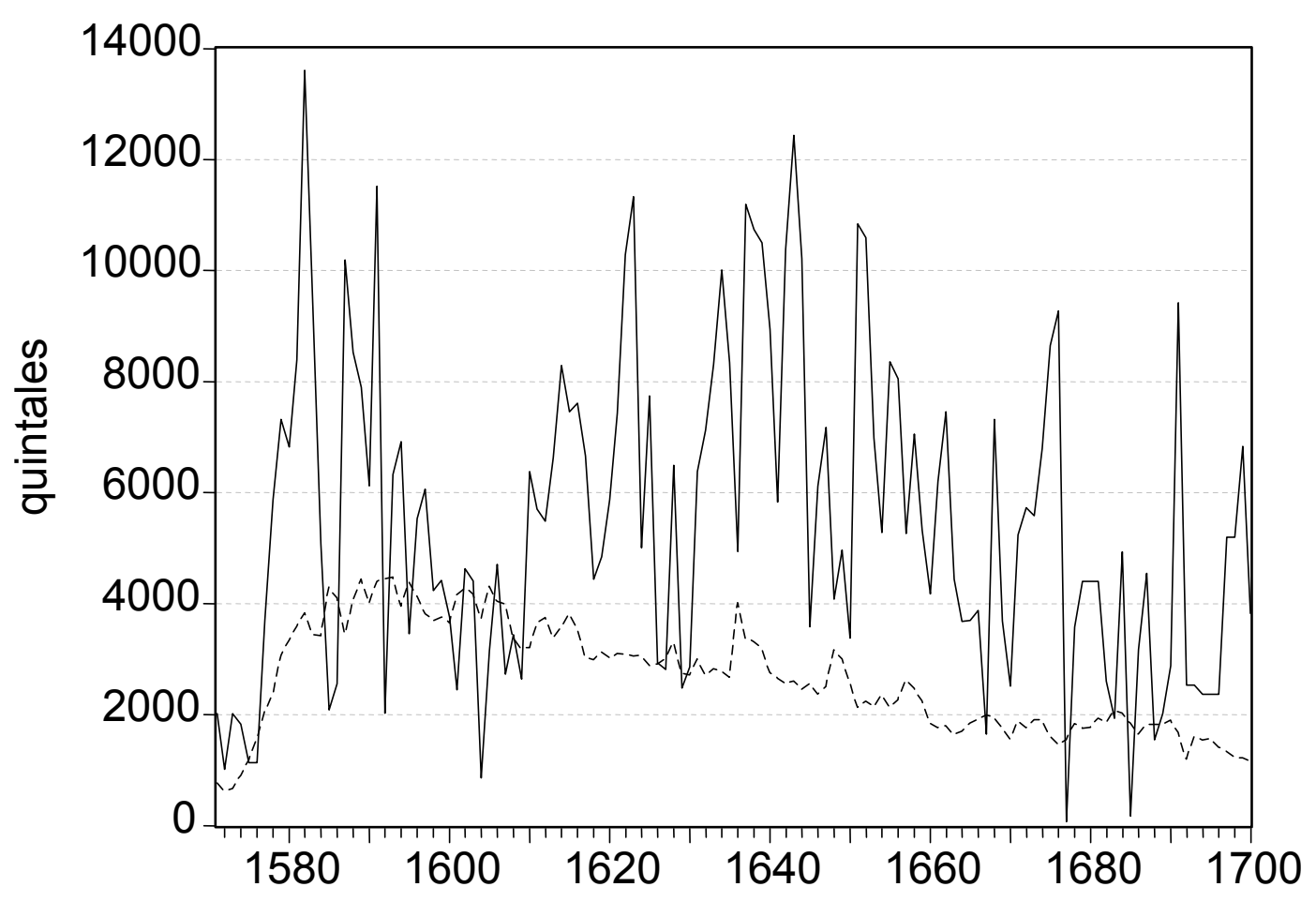

$\mathrm{Hg}-\cdots \mathrm{Ag}$

Fuentes: "Manifiesto", en Moreyra, La moneda, 263 y s.s; "Razón del azogue que se ha sacado de la Real Mina de Guancabelica y enterado y quintado en las Reales Cajas della" (BNM, Ms. 2784, f ${ }^{\circ} 517 / 20$ ). Citado en Guillermo Lohmann Villena, Las minas de Huancavelica (Sevilla: Escuela de Estudios Hispano-Americanos, 1949), 452; Mervyn F. Lang, El monopolio estatal del mercurio en el México colonial (México: FCE, 1977), 353,354; Contreras, El azogue, passim.

Sin desconocer otros argumentos, mi hipótesis es que los "mayores consumos de azogue" representan una aproximación al margen de fraude. Debe tenerse presente, que estas cantidades estan extraídas según los inventarios disponibles y suponen una aproximación a la cuestión en forma contable. Estadísticamente, como variable continua en el tiempo, lo analizamos en la sección siguiente. 


\section{El comportamiento de la relación azogue/plata en el tiempo}

Hemos calculado una serie cronológica del azogue disponible ${ }^{48}$, para confrontarla con la producción de plata registrada; es decir, aquélla que pasó por las Cajas Reales. Como resultado observamos gráficamente un notorio exceso del volumen de azogue sobre el de plata (ambas están medidas en las misma unidades: quintales). Ese exceso no solamente se mantiene, sino que aumenta aún cuando la producción de plata registrada decrece. El análisis de la relación se observa en el gráfico $n^{\circ} 5$. Aquí la serie cronológica ha sido descompuesta en sus dos elementos: tendencia y fluctuaciones; las áreas sombreadas corresponden a las etapas antes señaladas ${ }^{49}$.

Comencemos por las fluctuaciones. Hasta 1604 la relación desciende y es congruente con nuestras apreciaciones sobre la denominada $1^{\text {a }}$ Etapa. Luego, hay un ascenso en el consumo de azogue en relación a la plata, que llega a "picos" entre 1640 y 1652. Esa es precisamente la "época turbulenta"; se exteriorizó el fraude perpetrado por Fernando Gómez de la Rocha y acontecieron las muertes de Nestares Marín y Francisco de la Cruz. Posteriormente, la relación presenta altibajos, presuntamente vinculados con las exportaciones de mercurio reanudadas en 1670 y que representaron el $17,5 \%$ de la producción de las minas de Huancavelica ${ }^{50}$.

\footnotetext{
${ }^{48}$ Azogue disponible $=$ Producción + Importaciones - Exportaciones

${ }^{49}$ Las tendencias han sido calculadas luego de "suavizar" los datos mediante el método de las medias móviles. Los datos "suavizados" fueron ajustados por el método de lo mínimos cuadrados mediante polinomios de tercer orden. Las fluctuaciones surgen por diferencia, entre la tendencia y los datos.

${ }^{50}$ Lang, El monopolio, 354.
} 


\section{GRAFICO N ${ }^{\circ}$ \\ RELACION AZOGUE/PLATA \\ TENDENCIA Y FLUCTUACIONES}

(1571-1700)

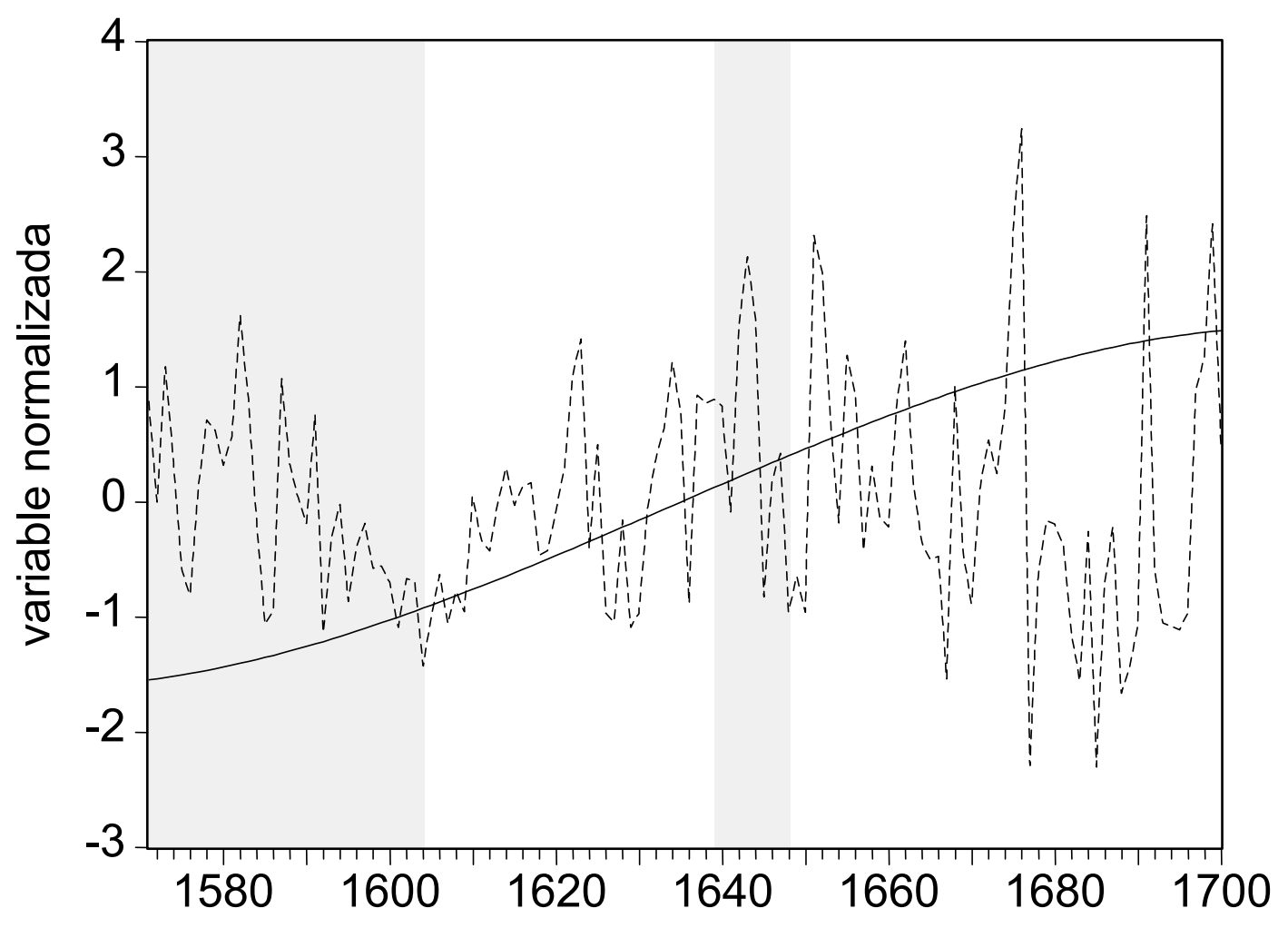

\section{$\mathrm{Hg} / \mathrm{Ag}$ - Tendencia $\cdots \mathrm{Hg} / \mathrm{Ag}$ - Fluctuaciones}

Fuentes: "Manifiesto", en Moreyra, La moneda, 263 y s.s; "Razón del azogue que se ha sacado de la Real Mina de Guancabelica y enterado y quintado en las Reales Cajas della“ (BNM, Ms. 2784, $\mathrm{f}^{\circ} 517 / 20$ ). Citado en Guillermo Lohmann Villena, Las minas de Huancavelica (Sevilla: Escuela de Estudios Hispano-Americanos, 1949), 452; Mervyn F. Lang, El monopolio estatal del mercurio en el México colonial (México: FCE, 1977), 353,354; Contreras, El azogue, passim; cuadro no. 1.

La tendencia refleja un crecimiento de la relación azogue/plata a lo largo del siglo pero sus variaciones no son uniformes. Se acelera y luego se desacelera, conforme observamos con mayor precisión en el gráfico $\mathrm{N}^{\circ} 6^{51}$. El área sombreada corresponde al período entre 1621 y

\footnotetext{
${ }^{51}$ La curva es la derivada de la tendencia indicada en el cuadro $\mathrm{N}^{\circ} 1$.
} 
1644 cuando la velocidad de crecimiento de esa relación tiene mayores magnitudes. En otras palabras, es cuando se incrementa notablemente la relación azogue/plata. También coincide con las apreciaciones de Lang sobre las dificultades de Huancavelica ${ }^{52}$. ¿Dificultades de la mina o aumento del consumo por la producción de plata no registrada? Si el mayor consumo de azogue hubiese respondido a un problema de la ley del mineral, exclusivamente, la velocidad de crecimiento de la relación azogue/plata, no presentaría esa aceleración para luego desacelerarse. No hay explicación técnica suficiente para ello.

\section{GRAFICO N6 \\ RELACION AZOGUE/PLATA \\ VARIACIONES DE LA TENDENCIA \\ (1571-1700)}

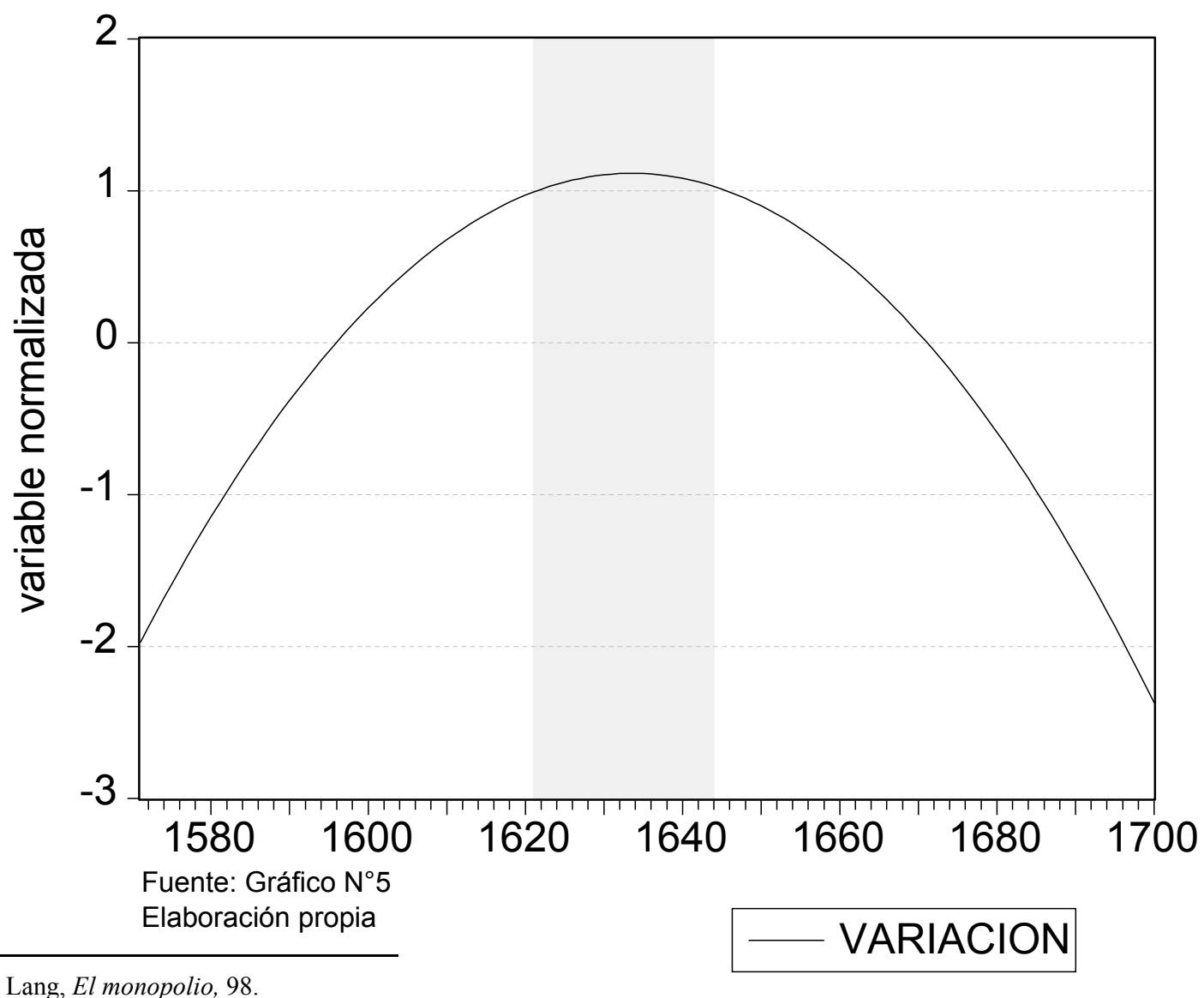


La racionalidad debemos buscarla en la relación entre los azogueros y los funcionarios que conducían el monopolio estatal. Esos productores obtenían azogue conforme registraban la plata en las Cajas Reales, en una proporción 2:1, que era una relación institucional. Si el rendimiento técnico, como parece, era menor que esa relación institucional, la diferencia permitía la producción de plata sin registrar, como indicaremos más abajo en el gráfico $\mathrm{N}^{\circ} 7$

\section{Recapitulación y conclusiones}

Sobre los fraudes en perjuicio de la Corona no hay mayores discusiones. Se acepta que hubo contrabando, entendido como violación del monopolio español; que existieron producciones no registradas de plata y azogue; que el sistema de la mita toledana degeneró para convertirse en un subsidio a los mineros. Todo ello es conocido.

Mi propuesta es revisar esos aspectos desde otro ángulo: el margen de fraude. Todas esas "violaciones" eran toleradas, dentro de ciertas pautas de flexibilidad que permitía el sistema ${ }^{53}$. De otra forma no se explica el "eje comercial marginal" Potosí-Buenos Aires ${ }^{54}$.

Y la manera más obvia de financiar esa "economía informal" es con plata sin quintar; es decir, evadiendo el impuesto correspondiente. ¿Para qué pagar quintos, Cobos y señoreaje si los medios de pago van a ser utilizados en un comercio "ilegal"? Por otra parte, el tráfico interno se realizaba generalmente en barras de plata y plata piña. ${ }^{55}$

La relación azogue/plata es una buena aproximación para delimitar el rango de fluctuación del fraude. Si bien es difícil establecer el perdido (o merma del proceso de patio) por encima del consumido de acuerdo con las razones químicas, es a todas luces exagerado suponer la existencia de mermas que superan el $100 \%{ }^{56}$

El gráfico que se inserta a continuación, compara la tendencia correspondiente a la serie cronológica de la plata registrada en las Cajas Reales, con la proyección derivada del azogue disponible. La base de esa proyección fue la relación azogue/plata de 1,75:1, para nuestra

\footnotetext{
${ }^{53}$ El puerto de Buenos Aires se desarrolló prácticamente al margen de la ley (Cf. Zacarías Moutoukias, Contrabando y control colonial en el siglo XVII (Buenos Aires: Centro Editor de América Latina, 1986) con un volumen de tráfico "comparable al efectuado entre España y el Virreinato del Perú". Ibídem, 167.

${ }^{54}$ Cf. Salles, "Santiago y Buenos Aires".

${ }^{55}$ Cf. Hector Omar Noejovich, "Los usos monetarios y la segmentación social: un ensayo diacrónico sobre la historia monetaria del virreinato del Perú y la República del Perú", en J. Pujol, P. Fatjo y N. Escandell, eds., Cambio institucional e Historia económica (Barcelona: Universidad Autónoma, 1996). También Franklin Pease, y Héctor Omar Noejovich, "La cuestión de la plata en los siglos XVI-XVII", Histórica, XXIV, no. 2 (2002).

${ }^{56}$ La fundición de metales no ferrosos por sistemas manuales, aún en la actualidad, es un arte. Las mermas varían de fundidor a fundidor. Sin embargo, estas variaciones fluctúan en rangos estimables, cuya varianza no es superior al promedio. Cuando la varianza es exagerada y superior a la media, se presume la existencia de fraude.
} 
denominada $2^{\mathrm{a}}$ etapa (1604-1639). Para los períodos siguientes se tomó 2:1, esto es un perdido del $100 \%$. Creo que esta estimación es "generosa" para los mineros.

\section{GRAFICO No7 \\ COMPARACION DE LAS TENDENCIAS DE PRODUCCION DE PLATA: \\ REGISTRADA Y PROYECTADA SEGUN CONSUMO DE AZOGUE Potosí (1605-1700)}

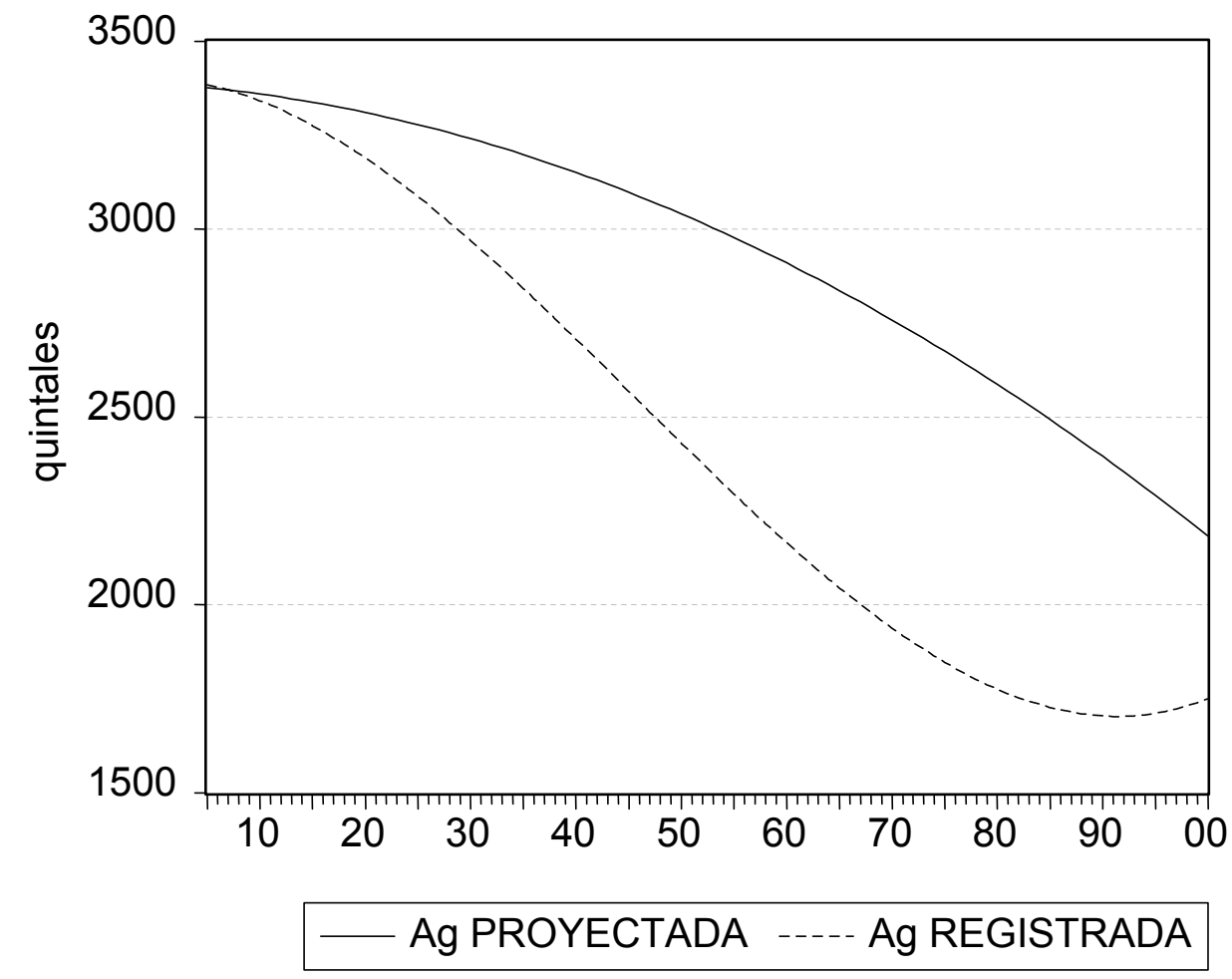

Fuente: Héctor Omar Noejovich, "Producción de plata y consumo de azogue: una comparación entre el virreinato del Perú y el virreinato de la Nueva España bajo los Austrias, Investigación Económica XLI, no.235 (2001): 161-199.

Podemos observar como se ensancha el margen de fraude a lo largo del siglo XVII, contrayéndose en los últimos veinte años del mismo. Aparentemente las administraciones virreinales del Duque de la Palata (1681-1689) y del Conde de la Monclova (1689-1705), además de las exportaciones a México, pusieron los límites a ese margen, a través de medidas adoptadas, que no es el caso discutir en este trabajo. 
Existen algunos tópicos sobre los cuales deseamos enfatizar:

(1) Existió una relación azogue/plata que denominamos institucional y que provenía de una "negociación" entre los mineros y las autoridades, respecto de la "cuota de azogue", relacionada con el "registro de plata" en las Cajas Reales. Esta relación vinculaba a ambas en una proporción que no respondía a cánones técnicos. Esta es la usualmente citada en la historiografía, de una libra de azogue por un marco de plata.

(2) Había, por otro lado, una relación técnica proveniente del "proceso de patio" que difiere de la anterior, según las fuentes consultadas. Esta era fluctuante, dependiendo de la eficiencia del proceso, el cual, en definitiva, descansa en una relación química, desconocida en la época, pero que puede estimarse de la documentación existente.

(3) De esta forma, la diferencia entre la relación institucional y el consumo de azogue, iba en beneficio del azoguero. En efecto, si con 1 marco de plata obtengo una cuota de 2 marcos de azogue, pero si sólo utilizo, por ejemplo, 1,5 marcos de azogue, con esa cuota puedo producir 1,33 marcos de plata y asi sucesivamente.

(4) La diferencia indicada en el punto anterior, permitía una producción de plata mayor que, obviamente, no había necesidad de registrar y abonar las tasas correspondientes. A ello, debemos añadir la denominada plata piña, que provenía de la corpa que captaban los indígenas para su propio provecho ${ }^{57}$.

(5) Mi propio concepto de corrupción se aleja de la concepción usual. Hay un sistema que coherentemente "relativiza el cumplimiento de las normas" y genera aquello que denomino margen de fraude y que he intentado medir contrastando la producción de plata registrada y la que deriva del consumo de azogue. No se puede hablar, entonces, de corrupción en el sentido moderno. Era todo un sistema basado en una "dualidad" de comportamientos que, por coincidencia, se adaptó muy bien al sistema indígena.

(6) Finalmente, ese margen de fraude dio origen a un proceso de desarrollo interno, especialmente hacia el sur de Potosí y en dirección a Buenos Aires, que se convirtió en el centro del contrabando, entendido como la violación del monopolio comercial sevillano.

Creo que esta es una línea de investigación con capacidad para aportar a la comprensión de la historia colonial en el virreinato del Perú, durante la dinastía de los Habsburgo.

\footnotetext{
${ }^{57}$ Terminada su jornada semanal, los indígenas que trabajaban en las minas tenían derecho a entrar al socavón y extraer mineral por su cuenta.
} 


\section{Bibliografía}

Acosta, Joseph de. Historia moral y natural de las Indias, Edición de Edmundo O'Gorman. México: FCE, 1962 [1590].

Belshaw, Cyril. Comercio tradicional y mercados modernos. Barcelona: Labor, 1972.

Bernbecker, Walter L. "Contrabando, legalidad y corrupción en el México decimonónico", Historia y Grafia 1, no. 1 (1998).

Bruchard, Roderick E. "Coca y trueque de alimentos". En Reciprocidad e intercambio en los Andes, Giorgio Alberti y Enrique Mayer, eds. Lima: Instituto de Estudios Peruanos, 1974.

Cobb, Gwendolyn Ballantine. Potosi y Huancavelica. La Paz: Banco Minero de Bolivia, 1977.

Cole, Jeffrey A. The Potosi Mita, 1573-1700. Stanford: Stanford University Press, 1985.

Contreras Carranza, Carlos. El azogue en el Perú colonial, 1570-1650. Tesis inédita. Lima: Pontificia Universidad Católica, 1981.

Fisher, John. Minas y mineros en el Perú colonial. Lima: Instituto de Estudios Peruanos, 1977.

Glave, Luis Miguel. "El virreinato peruano y la llamada 'crisis general' del siglo XVII". En Las crisis económicas en la historia del Perú, Heraclio Bonilla, ed. Lima: Fundación Friedrich Ebert, 1986.

Godelier, Maurice. Racionalidad e irracionalidad en economía. México: Siglo XXI, 1976.

Lang, Mervyn F. El monopolio estatal del mercurio en el México colonial. México: FCE, 1977.

Levene, Ricardo. Introducción a la historia del Derecho Indiano. Buenos Aires: Valerio Abeledo, 1976.

Lohmann Villena, Guillermo. Las minas de Huancavelica. Sevilla: Escuela de Estudios Hispano-Americanos, 1949.

Matienzo, Gobierno del Perú. París-Lima: Instituto Francés de Estudios Andinos, 1967 [1567].

Moreyra, Manuel y Paz Soldan. La moneda colonial en el Perú. Lima: Banco Central de Reserva, 1980.

Moutoukias, Zacarías. Contrabando y control colonial en el siglo XVII. Buenos Aires: Centro Editor de América Latina, 1986.

"Power, Corruption, and Commerce: The Making of the Local Administrative Structure in Seventeenth Century Buenos Aires", Hispanic American Historical Review 668, no. 4 (1988): 771-801.

Murra, John V. ed., Visita a la provincia de León de Huánuco en 1562. Iñigo Ortiz de Zuñiga, visitador. 2 t. Huánuco: Universidad Nacional Hermilio Valdizán, 1967.

Noejovich, Héctor Omar. "El pensamiento dual andino y sus implicaciones socioeconómicas", Histórica XIX, no. 1 (1995).

Los albores de la economía americana. Lima: Fondo Editorial PUCP, 1996.

"Los usos monetarios y la segmentación social: un ensayo diacrónico sobre la historia monetaria del virreinato del Perú y la República del Perú". En Cambio institucional e Historia económica, J. Pujol, P. Fatjo y N. Escandell, eds. Barcelona: Universidad Autónoma, 1996. 
- "Normatividad, institucionalidad y tecnología: el comportamiento peculiar de agentes en la industria pesquera", Economía XIV, no.28 (1997).

"La política minera del virrey Toledo: un ensayo económico". Economía XIX, no. 37-38 (Junio de 1998).

"Producción de plata y consumo de azogue: una comparación entre el virreinato del Perú y el virreinato de la Nueva España bajo los Austrias", Investigación Económica XLI, no.235 (2001): 161-199.

Pease, Franklin y Héctor Omar Noejovich, "La cuestión de la plata en los siglos XVI-XVII", Histórica XXIV, no. 2 (2002).

Pietshmann, Horst. "Burocracia y corrupción en Hispanoamérica colonial. Una aproximación tentativa", Nova americana, no. 5 (1982):11-37.

Burocracia y corrupción. México: Fondo de Cultura Económica, 1987.

Ramos Gómez, Luis Jorge. "La acusación contra el Presidente Electo Dn. José Araujo y Río, sobre la introducción de mercancías ilícitas a su llegada a Quito en diciembre de 1736", Boletín de la Academia Nacional de Historia, no. 72 (1993).

Salles, Estela Cristina y Héctor Omar Noejovich. "Santiago y Buenos Aires: la actividad económica en la frontera sur del virreinato del Perú", Economía XXII, no. 43 (1999): 211-215.

Tandeter, Enrique. Coacción y Mercado. La minería de plata en el Potosí colonial, 1629-1826. Cusco: Centro de Estudios Regionales Andinos "Bartolomé de las Casas", 1992.

Torquemada, Juan. Monarquía Indiana. 3 vols. México: Porrúa, 1986 [1615].

Vacary de Venturini, Leticia. Sobre gobernadores y rendición en la Provincia de Venezuela. Siglos XVI, XVII y XVIII. Caracas: Academia Nacional de Historia, 1993. 